\title{
Self-perception of personal oral health in Saudi population: a social media approach
}

\author{
I. AlShahrani, ${ }^{1}$ S. Tikare, ${ }^{7}$ R.A. Togoo, ${ }^{7}$ Y.H. AlAsere ${ }^{7}$ and A.A. AlAsmari ${ }^{7}$
}

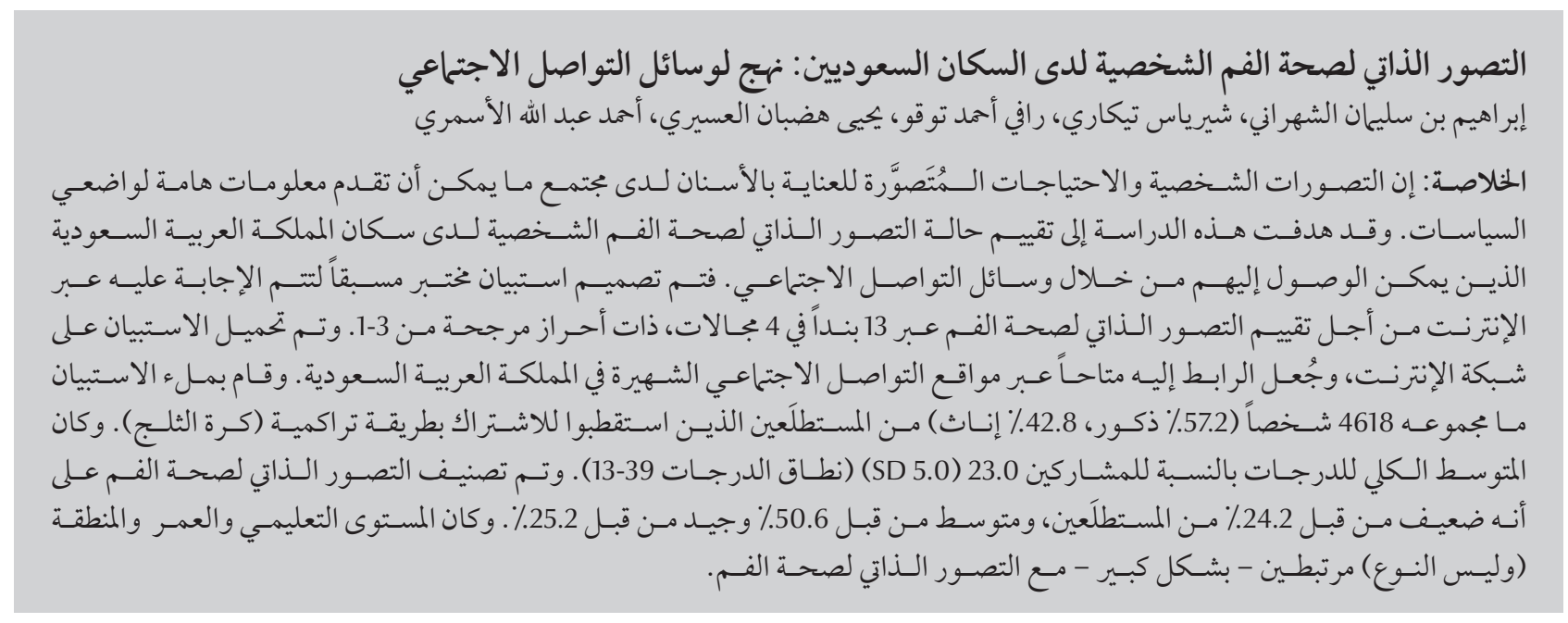

ABSTRACT Subjective perceptions and perceived needs for dental care in a population can provide important information for policy-makers. This study aimed to assess self-perceived personal oral health status among the Saudi Arabia population who could be accessed through social media. A pre-tested questionnaire for completion online was designed to assess self-perceived oral health via 13 items in 4 domains with weighted scores from 1-3. The questionnaire was uploaded to the Internet and the link to it was made available through popular social networking sites in Saudi Arabia. With respondents recruited by snowball methods a total of 4618 people (57.2\% males, $42.8 \%$ females) completed the questionnaire. The total mean score for the participants was 23.0 (SD 5.0) (scale range 13-39). Self-perceived oral health was rated as poor by $24.2 \%$ of respondents, average by $50.6 \%$ and good by $25.2 \%$. Educational level, age and region but not sex were significantly associated with self-perceived oral health.

Auto-perception de la santé bucco-dentaire personnelle dans la population saoudienne : approche par les médias sociaux

RÉSUMÉLes perceptions subjectives etles besoins perçus en matière de soins bucco-dentaires dans une population peuvent fournir des informations importantes pour les responsables de l'élaboration des politiques. La présente étude visait à évaluer l'état de santé bucco-dentaire perçue par l'individu dans la population saoudienne utilisant les médias sociaux. Un questionnaire préalablement testé et destiné à être rempli en ligne a été élaboré pour l'évaluation de la santé bucco-dentaire perçue par l'individu, au moyen de 13 items dans quatre domaines ayant des scores pondérés compris entre 1 et 3 . Le questionnaire a été mis en ligne et le lien a été rendu accessible sur des sites de réseaux sociaux populaires en Arabie saoudite. Grâce à l'effet d'entraînement pour recruter les répondants, 4618 personnes (57,2\% d'hommes, 42,8 \% de femmes) au total ont rempli le questionnaire. Le score moyen total des participants était de 23,0 (ET 5,0) (extrêmes : 13-39). La santé bucco-dentaire a été auto-évaluée comme mauvaise par 24,2 \% des répondants, comme moyenne par 50,6 \% et comme bonne par 25,2 \%. Le niveau d'études, l'âge et la région étaient significativement associés à l'état de santé bucco-dentaire perçu par l'individu, mais pas le sexe. 


\section{Introduction}

Oral health is essential to general health and quality of life. According to the World Health Organization, oral health is "a state of being free from mouth and facial pain, oral and throat cancer, oral infection and sores, periodontal (gum) disease, tooth decay, tooth loss, and other diseases and disorders that limit an individual's capacity in biting, chewing, smiling, speaking, and psychosocial wellbeing" (1). Contemporary concepts of health suggest that oral health should be defined in terms of general physical, psychological and social well-being in relation to oral status (2). Poor oral health affects quality of life as a result of pain or discomfort, tooth loss, impaired oral functioning, disfigurement, missing school time, loss of work hours and even death (in the case of oral cancers). Oral health also has an effect on many chronic diseases (2-5). Although oral health in many countries has improved considerably in recent decades, with a declining trend of dental caries, it appears to be showing a rising trend, especially in developing countries, thus widening inequities in oral health (6-8) Reducing such inequalities in health has become a major focus for government health policy (9-11).

The most common oral diseases worldwide that a majority of people suffer to some extent in a lifetime are dental caries and periodontal disease (1). Current definitions for states of illhealth, however, include dimensions of psychological and social well-being and not just general physical interpretations. Similarly, the concept of health-care needs assessment has now extended to include subjective perceptions and patients' own attitudes towards ill-health rather than exclusively the objective clinical interpretation of the health-care professional (12). Oral health needs that are identified only by the professional have some serious limitations; they tell us nothing about functioning of the oral cavity or subjective perceptions such as pain and discomfort. For example, losses of molar teeth do not necessarily mean there is a need for dental treatment unless the patient has functional impairment affecting his/her oral health-related quality of life. Hence, subjective perceptions and perceived needs for dental care add an important dimension to the concept of dental need. More recent literature emphasizes the importance of patients' feelings and priorities about health-care $(13,14)$. Furthermore, people who perceive a need for dental treatments are most likely to benefit from the provision of treatment and may be considered as a high-priority group at a time of scarce resources (15).

Oral diseases are highly prevalent in Saudi Arabia. There have been several surveys conducted locally to determine the nature and magnitude of oral health problems in the provinces. The current literature shows that a majority of oral health surveys have been done on child populations (16-20). These individual investigations are based on normative assessments and hence may not address oral health status completely at the national level. The present study attempts to fill the lacunae of information about national oral health status in Saudi Arabia.

The objective of this survey was to assess self-perceived personal oral health $(\mathrm{SPOH})$ status among the Saudi Arabia population. Self-reported aspects of oral health in the absence of clinical data can reflect the relative magnitude of oral health problems in the country. Such a survey may provide important information for policy-makers in the planning and evaluation of oral health-care services.

\section{Methods}

\section{Study design and population}

The study used an Internet-based Arabiclanguage questionnaire, with participants self-recruited by snowball sampling via social media networking sites. Our study was aimed at all Saudi nationals residing in Saudi Arabia above 10 years of age who could be accessed through social networking sites. The total population of Saudi Arabia is 27.3 million with more than $30 \%$ expatriates. The native population is approximately 19.1 million and those above 10 years of age are estimated at around 13 million (21).

\section{Questionnaire}

A draft questionnaire to assess $\mathrm{SPOH}$ was constructed in English and translated into the national language (Arabic). The questions focused on the most commonly occurring oral diseases: dental caries and periodontal disease. The $\mathrm{SPOH}$ questionnaire was designed to collect basic sociodemographic information and to assess SPOH with 13 items in 4 domains: knowledge ( 5 items), function (3 items), quality of life ( 2 items) and social aspects ( 3 items) (Table 1 ). The responses for each item in the questionnaire carried weightings. The response options indicating poorest knowledge, oral function disabilities and highest impact on social and quality of life aspects were given the highest weighted scores. The total score obtained by all items in the questionnaire indicated a measure of $\mathrm{SPOH}$ for an individual. The range of possible scores was 13 to 39 , with higher total scores indicating poorer $\mathrm{SPOH}$. The $\mathrm{SPOH}$ status of respondents was categorized using quartile values for the total score: quartile $1=$ good $\mathrm{SPOH}$, quartiles $1-3=$ average $\mathrm{SPOH}$ and quartile $3=$ poor $\mathrm{SPOH}$.

Both English and Arabic versions of the questionnaire were checked several times by language experts for clarity in the translated version and then verified for face validity by the faculty members of the Department of Dental Public Health at King Khalid University. The internal consistency of the total questionnaire items was found to be satisfactory (Cronbach alpha $=0.79$ ).

\section{Sampling and data collection}

After testing, the questionnaire was uploaded into a professional online survey 


\begin{tabular}{|c|c|c|c|}
\hline Domain/items $s^{a}$ & Score 1 & Score 2 & Score 3 \\
\hline \multicolumn{4}{|l|}{ Knowledge } \\
\hline \multicolumn{4}{|l|}{ Do you know it is important to use fluoridated toothpaste? } \\
\hline \multicolumn{4}{|l|}{ Do you know how to avoid cavities? } \\
\hline Do you know the mechanism behind loose teeth/gum disease? & Yes & Yes, in parts & No \\
\hline \multicolumn{4}{|l|}{ Do you know how to avoid loose teeth/gum disease? } \\
\hline \multicolumn{4}{|l|}{ Do you know the mechanism behind cavities? } \\
\hline \multicolumn{4}{|l|}{ Function } \\
\hline \multicolumn{4}{|l|}{ Do you have difficulties in chewing food due to problems in your mouth? } \\
\hline Do you have headache due to problems in your teeth/ mouth? & No, never & $\begin{array}{l}\text { Yes, } \\
\text { sometimes }\end{array}$ & $\begin{array}{l}\text { Yes, several } \\
\text { times }\end{array}$ \\
\hline \multicolumn{4}{|l|}{ Do you have shooting pain from warm or cold food or drink? } \\
\hline \multicolumn{4}{|l|}{ Quality of life } \\
\hline \multicolumn{4}{|l|}{ Have you ever felt bad or been ashamed of your mouth? } \\
\hline \multicolumn{4}{|l|}{ Have you ever felt depressed due to your teeth or mouth? } \\
\hline \multicolumn{4}{|l|}{ Social aspects } \\
\hline \multicolumn{4}{|l|}{ Have you ever avoided laughing due to problems with your teeth or mouth? } \\
\hline $\begin{array}{l}\text { Have you ever avoided normal socializing due to problems with your teeth or } \\
\text { mouth? }\end{array}$ & No, never & $\begin{array}{l}\text { Yes, } \\
\text { sometimes }\end{array}$ & $\begin{array}{l}\text { Yes, several } \\
\text { times }\end{array}$ \\
\hline Have you ever felt embarrassed due to your teeth or mouth? & & & \\
\hline
\end{tabular}

${ }^{a}$ The Arabic version of the questionnaire was used for the survey.

software tool (SurveyMonkey) (22). The link to complete the questionnaire online was made available through the 2 most popular social networking sites in Saudi Arabia: Twitter and Facebook. Information about the age and nationality criteria for participating in the survey (Saudi nationality and aged over 10 years) and about the confidentiality of responses was made clear in the covering letter. All the participants were requested to forward the link to their friends and families to recruit as many participants as possible. The time duration of the survey was fixed for 2 months from 1 November 2013 to 31 December 2013. We also posted requests on the same social media in order to remind the participants to fill the questionnaire. The responses collected were retrieved from the online survey software for analysis after the closing date of the survey.

\section{Statistical analysis}

The statistical software Stata, version 9.2 was used for the analysis. The $\mathrm{SPOH}$ are presented as mean and standard deviation (SD) total scores. One-way analysis of variance (ANOVA) was used to compare total $\mathrm{SPOH}$ scores between the categories according to educational level, age and region. Newman-Keuls multiple post-hoc procedures were applied to determine pairwise differences in the total $\mathrm{SPOH}$ scores. The level of significance was set at $5 \%$.

\section{Results}

\section{Background sociodemographic characteristics}

A total of 4618 people completed the questionnaire during the timeframe of the survey. Table 2 shows the distribution of the respondents according to various characteristics. Among the respondents $57.2 \%$ were males and $42.8 \%$ were females. The response rate was relatively high from the southern (45.1\%) and central (25.6\%) regions and lowest from northern (3.7\%) region of Saudi Arabia. A majority of participants were in the age group 21-30 years $(51.0 \%)$ and the lowest above 40 years $(9.4 \%)$. A majority of respondents had achieved a graduate degree (63.9\%), followed by intermediate college $(22.8 \%)$ and high-school education (5.5\%).

\section{SPOH scores}

The total mean SPOH score for the participants was 23.0 (SD 5.0) (Table $3)$. Around one-quarter of the respondents (24.2\%) had poor SPOH, $50.6 \%$ average $\mathrm{SPOH}$ and $25.2 \%$ good $\mathrm{SPOH}$. The mean $\mathrm{SPOH}$ scores within the different domains were as follows: for knowledge 10.1 (SD 2.7); for function 4.9 (SD 1.4); for quality of life 3.6 (SD 1.4); and for social aspects 4.4 (SD 1.6).

\section{Sociodemographic variables associated with $\mathrm{SPOH}$}

Table 2 shows the comparisons of total SPOH scores between various sociodemographic categories. There was a significant difference in the total SPOH scores according to educational 


\begin{tabular}{|c|c|c|c|c|c|c|}
\hline \multirow[t]{2}{*}{ Variable } & \multirow[t]{2}{*}{ No. } & \multirow[t]{2}{*}{$\%$} & \multicolumn{2}{|c|}{ Total SPOH score } & \multirow[t]{2}{*}{$F$-value } & \multirow[t]{2}{*}{$P$-value } \\
\hline & & & Mean & SD & & \\
\hline Sex & & & & & & 0.272 \\
\hline Male & 2641 & 57.2 & 22.8 & 5.0 & & \\
\hline Female & 1977 & 42.8 & 23.0 & 4.9 & & \\
\hline Educational status & & & & & 50.71 & $<0.001$ \\
\hline Intermediate & 255 & 5.5 & 25.0 & 4.9 & & \\
\hline High school & 1053 & 22.8 & 23.8 & 4.7 & & \\
\hline Graduate & 2952 & 63.9 & 22.8 & 5.0 & & \\
\hline Postgraduate & 358 & 7.8 & 20.7 & 4.7 & & \\
\hline Age group (years) & & & & & 22.52 & $<0.001$ \\
\hline $10-20$ & 861 & 18.6 & 23.8 & 4.5 & & \\
\hline $21-30$ & 2357 & 51.0 & 22.9 & 5.1 & & \\
\hline $31-40$ & 968 & 21.0 & 22.9 & 4.9 & & \\
\hline$>40$ & 432 & 9.4 & 21.4 & 5.0 & & \\
\hline Region & & & & & 4.774 & $<0.001$ \\
\hline South & 2081 & 45.1 & 23.2 & 5.0 & & \\
\hline North & 172 & 3.7 & 23.0 & 4.9 & & \\
\hline East & 458 & 9.9 & 23.0 & 4.9 & & \\
\hline West & 723 & 15.7 & 23.1 & 4.9 & & \\
\hline Centre & 1184 & 25.6 & 22.4 & 4.9 & & \\
\hline Total & 4618 & 100.0 & 23.0 & 5.0 & & \\
\hline
\end{tabular}

$S D=$ standard deviation .

level, age and region (ANOVA, $P<$ 0.001 ). The SPOH scores for the subjects with intermediate schooling were significantly higher than those with postgraduate qualification (NewmanKeuls test, $P<0.05)$. Similar analysis by age revealed that the age group 10-20 years had the highest $\mathrm{SPOH}$ scores followed by $21-30$ years, $31-40$ years and $>40$ years $(P<0.05)$. The highest $\mathrm{SPOH}$ scores were observed in the southern and western provinces and the lowest in the central provinces $(P$ $<0.05)$. There was no statistical difference in $\mathrm{SPOH}$ scores between the sexes $(P>0.05)$.

Multiple linear regression analysis was done with $\mathrm{SPOH}$ against the independent variables. The factors educational qualification, age and region were found to be significantly associated with self-perceived oral health, whereas no significant relationship with sex was found $\left(R=0.202, R^{2}=0.041\right.$, adjusted $R^{2}=$ 0.040) (Table 4).

\section{Discussion}

Use of social media is still growing rapidly and has become an integral part of our daily lives. It continues to evolve and offers meaningful ways to engage with people concerning events or issues. Saudi Arabia is one of the leading countries on social media in the Arab world with more than 13 million users. As of the second quarter $2014,31 \%$ of the total population were active social media users (23); $51 \%$ were active on Twitter and $42 \%$ were active on Facebook (24). These numbers show a high online presence. From a research point of view this is important as the mass population are easily accessible. Our survey attracted 4618 responses from varying sex, age groups, regions and educational backgrounds.

The main finding of this survey was that only one-quarter of the sample perceived their oral health as good. The remaining three-quarters of participants perceived their oral health as either poor or average. Although the great majority of subjects had an average $\mathrm{SPOH}$ score, the wide range in each questionnaire domain indicates the need for essential curative treatments such as restoration of decayed teeth, gum treatment, removal of badly decayed or loose teeth, replacement of missing teeth and oral health education programmes.

According to the literature, negative $\mathrm{SPOH}$ is related to a greater number of missing teeth (25), a lower level of education (26), utilization of prosthetic services (27) and low dental-care attendance (28). The variation of SPOH scores between age groups in our survey might reflect variations in awareness levels of oral diseases or differences in expectations, with problems occurring whenever the reality falls short of expectations regarding oral health (29). Educational qualifications are one of the important determinants of oral health; better educated people are more likely to perceive oral health as important and to adopt 


\begin{tabular}{|c|c|c|c|c|}
\hline \multirow[t]{2}{*}{ Domain } & \multirow[t]{2}{*}{ Scale score range } & \multicolumn{3}{|c|}{ SPOH score } \\
\hline & & Mean & SD & Median \\
\hline Total & $13-39$ & 23.0 & 5.0 & 23 \\
\hline Knowledge & $5-15$ & 10.1 & 2.7 & 10 \\
\hline Function & $3-9$ & 4.9 & 1.4 & 5 \\
\hline Quality of life & $2-6$ & 3.6 & 1.4 & 3 \\
\hline Social aspects & $3-9$ & 4.4 & 1.6 & 4 \\
\hline
\end{tabular}

$S D=$ standard deviation .

good oral hygiene measures. The results of our study reflect similar observations about educational qualifications to other scientific literature $(30,31)$. Regional differences in $\mathrm{SPOH}$ reflect variations in the severity of oral diseases but also variations in socioeconomic and cultural factors. The lack of difference in $\mathrm{SPOH}$ between the sexes in our study may be due to their similar rates of oral health problems or to similar patterns of dental care-seeking behaviour.

Multiple linear regression analysis was done to understand the relationship of $\mathrm{SPOH}$ with the available factors in our survey. Educational level, age and region were found to be significantly associated with self-perceived oral health. It was observed that though the model was significant, the factors explained only $4 \%$ of the variation $\left(P=<0.05, R^{2}=0.0406\right)$. This can be explained by the possible omission of several other variables that might influence SPOH. However, the study of variables on $\mathrm{SPOH}$ was not the primary objective of the present survey.

The study methods had some advantages and disadvantages. Our survey took advantage of the ability of the Internet to provide access to individuals who would be difficult, if not impossible, to reach through house-to-house or face-to-face interviews. Online surveys eliminate the need for staff, stationery and other costs, such as those incurred through postage, printing and data entry (32). Respondents input their own data, and it is automatically stored electronically. Analysis thus becomes easier and can be streamlined and is available immediately. The respondents can answer questions to suit their own schedule and pace and can even start a survey at one time, stop and complete it later.

The majority of our respondents were in the age group $21-30$ years (51\%) which can be attributed to the fact that $60.1 \%$ of the population in Saudi Arabia are under the age of 30 years and because there is a high Internet usage (71\%) among this age group $(33,34)$. The high proportion of university graduates responding to our study $(63.9 \%)$ is comparable to results observed in similar research (50.3\%) (35). The location of King Khalid University, Abha, may have contributed to higher proportion of respondents from the southern region of Saudi Arabia (45.1\%) (36).

Establishing a sampling frame when researching an online community presents a number of challenges, however. Participation in any online surveys may be sporadic; some people are "regulars," who may make daily contributions to discussions, while others only participate intermittently. This makes it difficult to obtain an accurate sampling frame or an accurate estimate of the population characteristics. Self-selection bias is another limitation of online survey research $(37,38)$. In short, there is a tendency of some individuals to respond to an invitation to participate in an online survey, while others ignore it, leading to a possible bias. It should be noted that such limitations are not unique to this survey but are general to any online survey research. Despite the limitations of the sampling method, the study was successful in attracting participants from various sociodemographic backgrounds.

\section{Conclusions}

The results of our survey suggest a large proportion of the Saudi Arabian population with access to the Internet perceived their oral health as poor to average. We recommend effective use of social media to spread oral health awareness in the country. SPOH status is a potentially important outcome measure, especially for policy-makers, and better understanding of it may be used to improve oral health services and

\begin{tabular}{|c|c|c|c|c|c|c|}
\hline Variables & Beta & SE of beta & $\begin{array}{l}\text { Regression } \\
\text { coefficient }\end{array}$ & $\begin{array}{l}\text { SE of reg. } \\
\text { coefficient }\end{array}$ & $t$-value & $P$-value \\
\hline Intercept & - & - & 27.81 & 0.427 & 65.18 & $<0.001$ \\
\hline Regions & -0.052 & 0.015 & -0.150 & 0.042 & -3.556 & $<0.001$ \\
\hline Age groups & -0.087 & 0.015 & -0.510 & 0.086 & -5.961 & $<0.001$ \\
\hline Sex & -0.001 & 0.015 & -0.012 & 0.147 & -0.080 & 0.936 \\
\hline Education & -0.165 & 0.015 & -1.208 & 0.107 & -11.32 & $<0.001$ \\
\hline
\end{tabular}

$R=0.202, R^{2}=0.041$, adjusted $R^{2}=0.040, F(4,461)=48.91, P<0.05$, standard error $($ SE $)$ of estimate $=4.87$. 
national oral health. Further research is required to investigate important factors influencing self-perceived oral health.

\section{Acknowledgements}

The authors are thankful to all the participants. This survey could not have been possible without their cooperation and support.

Funding: None.

Competing interests: None declared.

\section{References}

1. Oral health. Fact sheet No. 318. April 2012 [Internet]. Geneva: World Health Organization; 2013 (http://www.who.int/mediacentre/factsheets/fs318/en/, accessed 24 March 2015).

2. Locker D. Concepts of oral health, disease and the quality of life. In: Slade GD, editor. Measuring oral health and quality of life. Chapel Hill: University of North Carolina, Dental Ecology; 1997. pp. 11-23.

3. Petersen PE. The World Oral Health Report 2003: continuous improvement of oral health in the 21st century-the approach of the WHO Global Oral Health Programme. Community Dent Oral Epidemiol. 2003 Dec;31(1) Suppl 1:3-23. PMID:15015736

4. Jackson SL, Vann WFJr, Kotch JB, Pahel BT, Lee JY. Impact of poor oral health on children's school attendance and performance. Am J Public Health. 2011 Oct;101(10):1900-6. PMID:21330579

5. Naito M, Yuasa H, Nomura Y, Nakayama T, Hamajima N, Hanada N. Oral health status and health-related quality of life: a systematic review. J Oral Sci. 2006 Mar;48(1):1-7. PMID:16617194

6. Watt R, Sheiham A. Inequalities in oral health: a review of the evidence and recommendations for action. Br Dent J. 1999 Jul 10;187(1):6-12. PMID:10452185

7. Petersen PE, Kandelman D, Arpin S, Ogawa H. Global oral health of older people-call for public health action. Community Dent Health. 2010 Dec;27(4) Suppl 2:257-67. PMID:21313969

8. Kwan S, Petersen PE. Oral health: equity and social determinants. In: Blas E, Sivansankara Kurup A, editors. Equity, social determinants and public health programmes. Geneva: World Health Organization; 2010. pp. 159-76.

9. A Canadian Oral Health Strategy. Federal, Provincial, Territorial Dental Director's working group meeting, Montreal, August 2005 [Internet]. Ottawa: Federal, Provincial and Territorial Dental Working Group; 2005 (http://www.fptdwg.ca/assets/ PDF/Canadian\%20Oral\%20Health\%20Strategy\%20-\%20Final. pdf, accessed 24 March 2015).

10. National oral health improvement strategy for priority groups: frail older people, people with special care needs and those who are homeless. Edinburgh: Scottish Government; 2012. (http://www.scotland.gov.uk/Resource/0039/00394171.pdf, accessed 24 March 2015).

11. Together for Health. A National Oral Health Plan for Wales 2013-18. Cardiff: Welsh Government; 2013. (http://wales.gov. uk/docs/phhs/publications/130318oralhealthplanen.pdf, accessed 24 March 2015).

12. Sheiham A, Tsakos G. Oral health needs assessment. In: Pine $\mathrm{CM}$, Harris R, editors. Community oral health. Berlin: Quintessence; 2007

13. Bowling A. Measuring health; a review of quality of life measurement scales. 2nd ed. Milton Keynes, UK: Open University Press; 1997,

14. Gherunpong S, Tsakos G, Sheiham A. A sociodental approach to assessing dental needs of children: concept and models. Int J Paediatr Dent. 2006 Mar;16(2):81-8. PMID:16430521

15. Locker D, Jokovic A. Using subjective oral health status indicators to screen for dental care needs in older adults. Community Dent Oral Epidemiol. 1996 Dec;24(6):398-402. PMID:9007357

16. Al Dosari AM, Wyne AH, Akpata ES, Khan NB. Caries prevalence and its relation to water fluoride levels among school- children in Central Province of Saudi Arabia. Int Dent J. 2004 Dec;54(6):424-8. PMID:15633498

17. Al-Malik MI, Rehbini YA. Prevalence of dental caries, severity, and pattern in age 6 to 7 -year-old children in a selected community in Saudi Arabia. J Contemp Dent Pract. 2006 May 1;7(2):46-54. PMID:16685294

18. Khan NB. Treatment needs for dental caries in schoolchildren in Riyadh, Saudi Arabia. A follow up study of the oral health survey. Saudi Med J. 2003 Oct;24(10):1081-6. PMID:14578973

19. Natto S, Baljoon M, Bergström J. Tobacco smoking and periodontal health in a Saudi Arabian population. J Periodontol. 2005 Nov;76(11):1919-26. PMID:16274311

20. Sabbagh HJ, Mossey PA, Innes NPT. Prevalence of orofacial clefts in Saudi Arabia and neighboring countries: A systematic review. Saudi Dent J. 2012 Jan;24(1):3-10. PMID:23960521

21. Saudi Arabia demographics profile 2014. Index Mundi [Internet]. (http://www.indexmundi.com/saudi_arabia/demographics_profile.html, accessed 24 March 2015).

22. SurveyMonkey" [Internet]. (https://www.surveymonkey.com, accessed 24 March 2015).

23. Penetration of selected social networks in Saudi Arabia as of 2nd quarter 2014. Statista [Internet]. (http://www.statista.com/ statistics/284451/saudi-arabia-social-network-penetration/, accessed 24 March 2015).

24. Social media usage in the Middle East, Saudi Arabia as the world top Youtube nation. Social4C [Internet]. (http://social4ce. com/blog/2013/05/03/social-media-bytes-6-social-mediausage-in-the-middle-east-saudi-arabia-as-the-world-topyoutube-nation/\#sthash.tcT2K9DE.dpuf, accessed 24 March 2015).

25. Mariño R, Schofield M, Wright C, Calache H, Minichiello V. Selfreported and clinically determined oral health status predictors for quality of life in dentate older migrant adults. Community Dent Oral Epidemiol. 2008 Feb;36(1):85-94. PMID:18205644

26. Tsakos G, Sheiham A, Iliffe S, Kharicha K, Harari D, Swift CG, et al. The impact of educational level on oral health-related quality of life in older people in London. Eur J Oral Sci. 2009 Jun;117(3):286-92. PMID:19583757

27. Steele JG, Sanders AE, Slade GD, Allen PF, Lahti S, Nuttall N, et al. How do age and tooth loss affect oral health impacts and quality of life? A study comparing two national samples. Community Dent Oral Epidemiol. 2004 Apr;32(2):107-14. PMID:15061859

28. Martins AM, Barreto SM, Silveira MF, Santa-Rosa TT, Pereira RD. Self-perceived oral health among Brazilian elderly individuals. Rev Saude Publica. 2010 Oct;44(5):912-22. PMID:20882263

29. Carr AJ, Gibson B, Robinson PG. Is quality of life defined by expectations or experience? BMJ. 2001;322:1240-3. PMID:11358783

30. Paulander J, Axelsson P, Lindhe J. Association between level of education and oral health status in 35-, 50-, 65- and 75-yearolds. J Clin Periodontol. 2003;30(8):697-704. PMID:12887338

31. Teodora T, Danila I. Socioeconomic status and oral health. J Prev Med. 2005;13(1-2):116-21.

32. Llieva J, Baron S, Healey NM. Online surveys in marketing research: pros and cons. Int J Mark Res. 2002;44(3):361-7. 
33. Latest statistical releases [Internet]. Riyadh, Saudi Arabia: Central Department of Statistics and Information. (hhttp://www. cdsi.gov.sa/english/, accessed 27 April 2015).

34. Internet usage in the Kingdom of Saudi Arabia. The second year (2008) report. Riyadh, Saudi Arabia: Communications and Information Technology Commission; 2008 (http://www. citc.gov.sa/English/Reportsandstudies/Studies/Documents/ IT\%20014\%20E\%20-\%20IndividualReport2008.pdf, accessed 27 April 2015).

35. Mohammed TS. Internet usage and user preferences in Saud Arabia. Journal of King Saud University Engineering Sciences. 2011;23:101-107.
36. Regions of Saudi Arabia [Internet]. Wikipedia (http:// en.wikipedia.org/wiki/Regions_of_Saudi_Arabia, accessed 27 April 2015).

37. Stanton JM. An empirical assessment of data collection using the Internet. Pers Psychol. 1998;51(3):709-25.

38. Thompson LF, Surface EA, Martin DL, Sanders MG. From paper to pixels: moving personnel surveys to the Web. Pers Psychol 2003;56(1):197-227. 